\title{
Isolation and Characterization of 13 Microsatellite Loci from Luculia pinceana (Rubiaceae), a Typical Distylous Species
}

\author{
Wei Zhou and Hong Wang \\ Key Laboratory of Biodiversity and Biogeography, Kunming Institute of \\ Botany, Chinese Academy of Sciences, Kunming, Yunnan 650204, China
}

\section{De-Zhu Li ${ }^{1}$}

Key Laboratory of Biodiversity and Biogeography, Kunming Institute of Botany, Chinese Academy of Sciences, Kunming, Yunnan 650204, China; and Plant Germplasm and Genomics Center, Germplasm Bank of Wild Species, Kunming Institute of Botany, Chinese Academy of Sciences, Kunming, Yunnan 650204, China

\section{Jun-Bo Yang}

Plant Germplasm and Genomics Center, Germplasm Bank of Wild Species, Kunming Institute of Botany, Chinese Academy of Sciences, Kunming, Yunnan 650204, China

\author{
Wei Zhou \\ Graduate School of the Chinese Academy of Sciences, Beijing 100049, China \\ Additional index words. Luculia pinceana, microsatellite, polymorphism
}

\begin{abstract}
Luculia pinceana Hook. (Rubiaceae) is a typical distylous species with dimorphic and long-styled monomorphic populations. Within this study, we developed 13 microsatellite markers from $L$. pinceana using a modified biotin-streptavidin capture method. Polymorphism of each locus was assessed in 30 individuals from four dimorphic populations and one monomorphic population. The average allele number of these microsatellites was 4.153 per locus ranging from three to seven. The observed and expected heterozygosities were from 0.040 to 0.840 and from 0.571 to 0.769 , respectively. Additionally, all 13 identified microsatellite markers were successfully amplified in its related species, L. yunnanensis, 10 of which showed polymorphism. These microsatellite markers could provide a useful tool for further study of the breeding system and the population genetic structure in this species and within other Luculia species.
\end{abstract}

Luculia Sweet is a small shrubby genus containing three species and is a member of the family Rubiaceae (tribe Cinchoneae). All the species have compact pink or white tubular flowers contained in a tight inflorescence. The flowers are sweetly fragrant. It is widely cultivated in gardens as ornamentals. Luculia pinceana Hook. is widely distributed throughout southwest China, Myanmar, India, and Vietnam (Luo et al., 1999). It occurs on

Received for publication 10 Feb. 2010. Accepted for publication 9 Mar. 2010.

This study was supported by the National Basic Research Program of China (973 Program, No. 2007CB411600) and the Large-scale Scientific Facilities of the Chinese Academy of Sciences (2009-LSF-GBOWS-01).

We are grateful to Zhi-Rong Zhang, Pan-Hui Huang, and Jie Liu for their kind help in the laboratory. We thank David Paterson from Royal Botanic Garden Edinburgh for revising an earlier version of the manuscript.

${ }^{1}$ To whom reprint requests should be addressed; e-maildzl@mail.kib.ac.cn. address a transition of mating patterns from disassortative mating to selfing and/or intramorph crossing (W. Zhou, H. Wang and D.Z. $\mathrm{Li}$, unpublished data). To further chase its population genetic structure and the evolutionary podogram of the breeding system, we developed 13 microsatellite markers from $L$. pinceana and tested their use in another Luculia species, L. yunnanensis $\mathrm{Hu}$, which is also a distylous species.

\section{Materials and Methods}

Genomic DNA samples of $L$. pinceana were extracted from silica gel-dried leaves using a CTAB methodology (Doyle and Doyle, 1990). The extracted DNA was dissolved in $30 \mu \mathrm{L}$ TE buffer. A microsatellite enriched library was then conducted using a modified biotin-streptavidin capture method (Chen et al., 2008). Total genomic DNA $(\approx 250$ to $500 \mathrm{ng}$ ) was completely digested with $2.5 \mathrm{U}$ of $\mathrm{Mse}$ I restriction enzyme (New England Biolabs Inc., Beverly, MA) and then ligated to an MseI amplified fragment length polymorphism adaptor (5'-TACTCAGGAC TCAT-3' $/ 5^{\prime}$-GACGATGAG TCCTGAG-3') using T4 DNA ligase (New England Biolabs). The digested-ligated fragments were diluted in a ratio of $1: 10$, and $5 \mu \mathrm{L}$ was used in amplification reaction with adaptor-specific primers (5'-GATGAGTCCTGAGTAAN-3'). Amplified DNA fragments, with a size range of 200 to 800 base pairs (bp), were enriched by magnetic bead selection with a 5-biotinylated $(\mathrm{AG})_{15}$ and $(\mathrm{AC})_{15}$ and $(\mathrm{AAG})_{10}$ probe (Zane et al., 2002). The recovered DNA fragments were reamplified with $M s e I-N$ primers. Polymerase chain reaction (PCR) products were purified using the EZNA Gel Extraction Kit (Omega Bio-Tek, Guangzhou, China). The purified DNA fragments were ligated into pBS-T II vector (Tiangen; Tiangen Biotech Co., Ltd., Beijing, China) and then transformed into DH5 $\alpha$ competent cells (Tiangen). The positive clones were tested by PCR using T3/ $\mathrm{T} 7$ and $(\mathrm{AC})_{10} /(\mathrm{AG})_{10} /(\mathrm{AAG})_{7}$ as primers. A total of 320 positive clones were sequenced with an ABI PRISM 3730XL DNA sequencer (Applied Biosystems Inc., Foster City, CA), of which 154 clones contained microsatellites. It was found that 73 primer pairs were suitable for primer designing using Primer 5.0 (Clarke and Gorley, 2001).

Polymorphism of all 73 microsatellite loci were assessed in 30 individuals of L. pinceana equal from four dimorphic populations (Yunnan, Jingdong: long. 24 $47^{\prime} \mathrm{N}$, lat. $100^{\circ} 30^{\prime} \mathrm{E}$; Y unnan, Lushui, Pianma: long. $25^{\circ} 58^{\prime} \mathrm{N}$, lat. $98^{\circ} 48^{\prime} \mathrm{E}$; Yunnan, Yongde: long. $24^{\circ} 07^{\prime} \mathrm{N}$, lat. $99^{\circ} 43^{\prime} \mathrm{E}$; Guangxi, Tianyang: long. $23^{\circ} 32^{\prime} \mathrm{N}$, lat. $\left.106^{\circ} 31^{\prime} \mathrm{E}\right)$ and one monomorphic population (Yunnan, Jinping: long. $22^{\circ} 53^{\prime} \mathrm{N}$, lat. $103^{\circ} 13^{\prime} \mathrm{E}$ ) in southwest China. The PCR reactions were performed in $20 \mu \mathrm{L}$ of reaction volume containing 50 to $100 \mathrm{ng}$ genomic DNA, $0.5 \mu \mathrm{M}$ of each primer, and $10 \mu \mathrm{L} 2 \times$ Taq PCR MasterMix [Tiangen; $0.1 \mathrm{U}$ Taq polymerase $/ \mu \mathrm{L}, 0.5 \mathrm{~mm} \mathrm{dNTP}$ each, $20 \mathrm{~mm}$ Tris- $\mathrm{HCl}$ (pH 8.3), $100 \mathrm{~mm} \mathrm{KCl,} 3 \mathrm{~mm}$ $\left.\mathrm{MgCl}_{2}\right]$. PCR amplifications were conducted 
Table 1. Characteristics of 13 microsatellite loci developed for Luculia pinceana $(\mathrm{n}=30)$ and cross-amplification in L. yunnanensis $(\mathrm{n}=5)$.

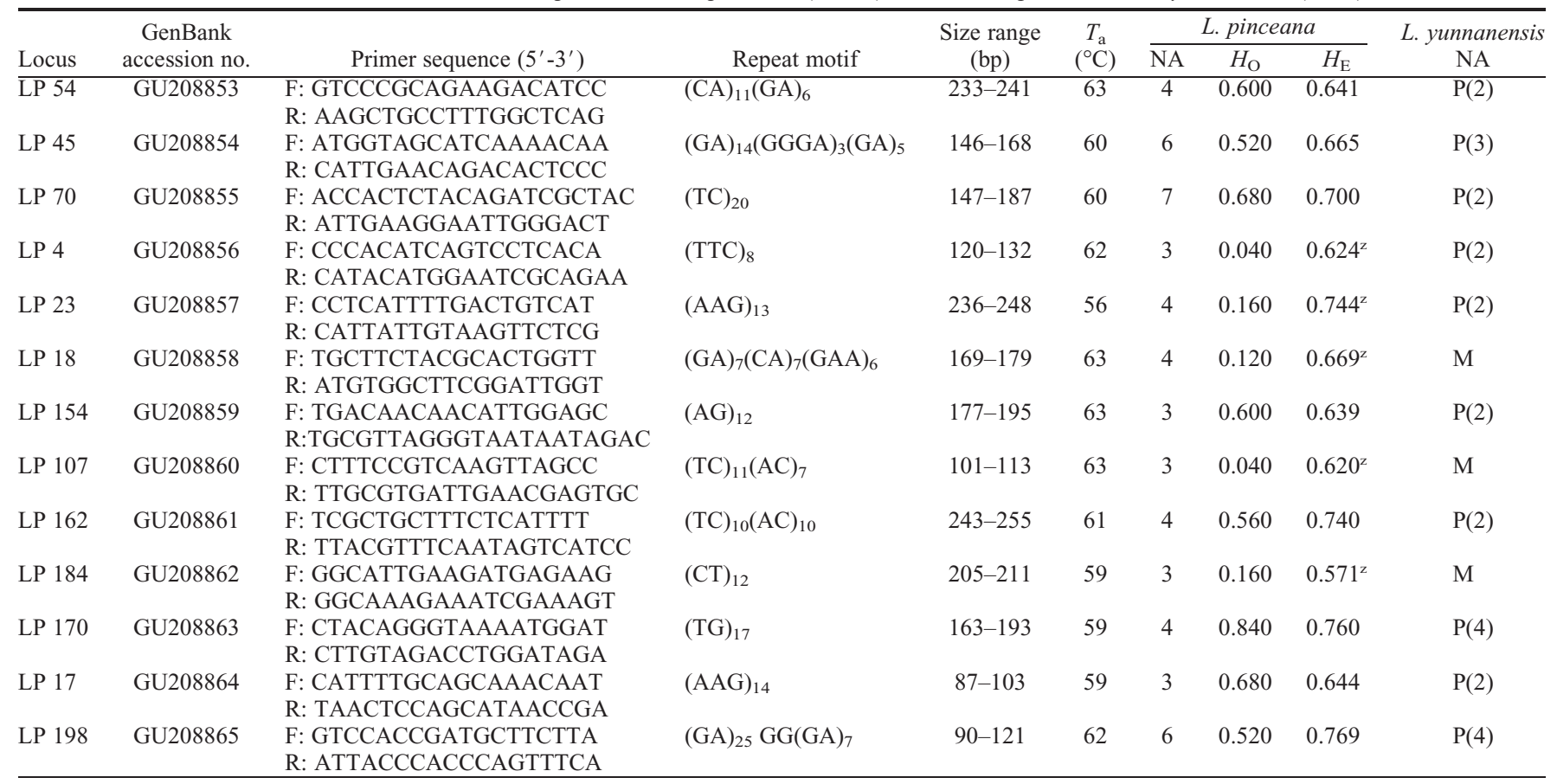

${ }^{2}$ Statistically significant deviation from Hardy-Weinberg equilibrium at $P<0.01$.

$T_{\mathrm{a}}=$ polymerase chain reaction annealing temperature; $\mathrm{NA}=$ number of alleles revealed; $H_{\mathrm{O}}=$ observed heterozygosity; $H_{\mathrm{E}}=$ excepted heterozygosity; $\mathrm{P}=$ polymorphic amplification; $\mathrm{M}=$ monomorphic amplification.

on an MJ PTC-200 Thermal Cycler (Waltham, MA) under the following conditions: $95^{\circ} \mathrm{C}$ for 5 min followed by 32 to 35 cycles at $94{ }^{\circ} \mathrm{C}$ for $45 \mathrm{~s}$ at the annealing temperature for each specific primer (optimized for each locus; Table 1) for $45 \mathrm{~s}, 72^{\circ} \mathrm{C}$ for $1 \mathrm{~min}$, and a final extension step at $72{ }^{\circ} \mathrm{C}$ for $7 \mathrm{~min}$. The PCR products were separated on $8 \%$ polyacrylamide denaturing gels using a $20-b p$ or 10-bp ladder molecular size standard (O'rangeRuler $^{\mathrm{TM}}$; Fermentas, Shenzhen, China) visualized by silver staining.

\section{Results and Discussion}

In all, PCR products with 13 primer pairs displayed polymorphism. Standard genetic diversity parameters, departure from HardyWeinberg equilibrium (HWE), and linkage disequilibrium (LD) between pairs of loci were estimated in POPGENE Version 4.0 (Raymond and Rousset, 1995). The number of alleles per locus was three to seven with an average of 4.153; values for observed and expected heterozygosities ranged from 0.040 to 0.840 and from 0.571 to 0.769 with averages of 0.424 and
0.675 , respectively (Table 1 ). For all 13 microsatellite loci, except LP 54, LP 45, LP 70, LP 154, LP 162, LP 170, LP 17, and LP 198, the genotypic frequencies showed significant deviation from HWE $(P<0.01)$ indicating the possibility of null alleles, the Wahlund effect, and the disassortative mating in a dimorphic population of this typical distylous species. LD $P$ values were obtained for 78 pairs of markers combinations. Of these, $20(25.64 \%)$ pairs showed significant LD at $P<0.01$.

Cross-species amplification in L. yunnanensis, which only has dimorphic populations in nature, was tested using five individuals (Yunnan, Fugong, Yaping: long. $27^{\circ} 01^{\prime} \mathrm{N}$, lat. $\left.98^{\circ} 49^{\prime} \mathrm{E}\right)$. All of the 13 identified microsatellite markers were successfully amplified and $10(76.92 \%)$ of them revealed polymorphism (Table 1). The results showed that there was a high potential for transferring microsatellite markers in the genus Luculia. The 13 novel polymorphic microsatellite loci developed here will be useful for further understanding the differentiation of population and evolution of distyly in $L$. pinceana and its related species.

\section{Literature Cited}

Barrett, S.C.H. and J.S. Shore. 2008. New insights on heterostyly: Comparative biology, ecology and genetics, p. 3-29. In: Franklin-Tong, V.E. (ed.). Self-incompatibility in flowering plants. Springer Press, New York, NY.

Chen, T., R.C. Zhou, X.J. Ge, and S. Shi. 2008 Development and characterization of microsatellite markers for a mangrove tree species Sonneratia caseolaris (L.) Engler (Lythraceae sensu lato). Conserv. Genet. 9:957-959.

Clarke, K.R. and R.N. Gorley. 2001. PRIMER version 5: User manual/tutorial. PRIMER-E Ltd., Plymouth, UK.

Doyle, J.J. and J.L. Doyle. 1990. Isolation of plant DNA from plant tissue. Focus 12:13-15.

Luo, X.R., W.Z. Gao, W.Q. Chen, X.H. Xu, and H. Wu. 1999. Rubiaceae, p. 238-242. In: Wu, Z.Y. and P.H. Raven (eds.). Flora of China. Vol. 71. Science Press, Beijing, China, and Missouri Botanical Garden, St. Louis, MO.

Raymond, M. and F. Rousset. 1995. GENEPOP (version 1.2): Population genetics software for exact tests and ecumenicism. J. Hered. 86:248249.

Zane, L., L. Bargelloni, and T. Patarnello. 2002. Strategies for microsatellite isolation: A review. Mol. Ecol. 11:1-16. 